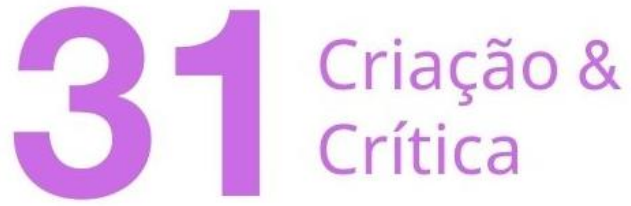

\section{SUBINDO O MORRO VELHO: NOTAS PARA A PREPARAÇÃO DE UMA PERFORMANCE}

\author{
William Teixeira ${ }^{1}$ \\ Juliana Araújo Gomes ${ }^{2}$ \\ Lucas Mateus Silva ${ }^{3}$ \\ Ricardo Magalhães Bulhões ${ }^{4}$
}

RESUMO: O artigo apresenta o relato da preparação de uma performance, pelos autores, da canção Morro Velho, composta por Milton Nascimento, mas aqui considerada em sua versão realizada por Elis Regina. Através de uma pesquisa artística de caráter experimental, o objetivo final da pesquisa em criar uma nova interpretação para a canção tem sua etapas de desenvolvimento aqui descritas. Além dos estágios de formulação da interpretação, apresentam-se as reflexões suscitadas e o diálogo com a literatura disponível para resolução de problemas, sobretudo as noções de análise imanente (Nattiez, 1990 e Ferraz, 2011), discurso lítero-musical (Costa, 2001) e a análise semiótica da gestualidade oral (Tatit, 2002).

\footnotetext{
${ }^{1}$ William é Bacharel em música com habilitação em violoncelo pela UNESP, Mestre em música pela UNICAMP e Doutor em música pela USP. Atualmente é Professor Adjunto da Universidade Federal de Mato Grosso do Sul, onde é Docente Permanente do Programa de Pós-Graduação em Estudos de Linguagem. Tem como área de pesquisa a Performance Musical em sua relação com os seguintes tópicos: análise da música contemporânea (da canção popular à música experimental); reflexões teológicas e filosóficas; repertório e técnica do violoncelo. E-mail: william.teixeira@ufms.br

2 Juliana iniciou seus estudos em música aos 7 anos, quando entrou no coral infantil de sua escola e decidiu que queria ser cantora. Aos 13 anos, estudou piano, aos 14, aprendeu a tocar violão, e, aos 17, baixo elétrico. Aos 18, formou sua primeira banda de rock. Atualmente, é graduanda do curso de Licenciatura em Música pela UFMS, onde desenvolve pesquisa de iniciação científica sobre a polifonia da voz cantada solo e segue em seu projeto solo como Jool Azul. E-mail: juliana.araujo@ufms.br

${ }^{3}$ Lucas Mateus Silva é músico, violonista e acadêmico do curso de Licenciatura em Música pela Universidade Federal de Mato Grosso do Sul (UFMS). Atualmente desenvolve um projeto de iniciação científica sob orientação do Prof. Dr. William Teixeira da Silva, intitulada "Viola caipira: dialogismos e reflexões sobre as possibilidades compositivas para o instrumento", onde busca compreender os processos criativos para a viola caipira através dos postulados teóricos de Mikhail Bakhtin. E também bacharel em Design pela Universidade Católica Dom Bosco (UCDB). E-mail: lucas.mateus@ufms.br

${ }^{4}$ Mestre e Doutor em Literatura e Vida Social pela UNESP de Assis, com pós-doutorado em Teoria Literária pela Unicamp (IEL); Professor de Literaturas de Língua Portuguesa na graduação e no PPG-Letras, Mestrado-Doutorado, na UFMS, no Campus de Três Lagoas (CPTL). Nos últimos cinco anos tem publicado trabalhos sobre a ficção brasileira contemporânea e suas relações intertextuais com outras épocas, propondo revisão e atualização das categorias da narrativa de romances e contos brasileiros do século XXI. Atualmente prioriza nas pesquisas os seguintes temas: literatura juvenil, literatura e ensino, literatura e outras artes (cinema, letra da canção, fotografia). É membro do Grupo de Pesquisa: A escrita no Brasil Colonial e suas relações (Unesp-Assis) e também faz parte do grupo de trabalho: Leitura e literatura infantil e juvenil junto a ANPOLL. E-mail: ricardoufms1@gmail.com
} 


\section{Criação \&}

Por fim, demonstra-se a importância de se considerar a performance tanto enquanto dado analítico, quanto como prática cuja realização é produtora de questões de pesquisa e de novas soluções para a significação.

Palavras-Chave: Milton Nascimento; Música Popular Brasileira; análise musical; análise de discurso; semiótica da canção.

\section{Climbing the Old Hill: Notes for a Performing Practice}

ABSTRACT: The paper presents a report of the preparation of a performance for the song Morro Velho, composed by Milton Nascimento, but considered in a version performed by Elis Regina. In addition to the stages of formulating the performance, it presents the reflections raised and the dialogue with the literature available for problem solving, especially the notions of immanent analysis (Nattiez, 1990 and Ferraz, 2011), literary-musical discourse (Costa, 2001) and the semiotic analysis of oral gestures (Tatit, 2002). Finally, it proves the importance of considering performance both as an analytical data and as a practice that produces research questions and new solutions for meaning.

KeYwords: Milton Nascimento; Brazilian Popular Music; Musical Analysis; Discourse Analysis; Song Semiotics.

A pandemia da Covid-19, que desde março de 2020 assola o mundo, tem causado danos nas mais variadas esferas da vida e, dentre as mais severas, na própria possibilidade de se pensar, fazer e experimentar a música. Justamente a música, que como uma ação comunitária demanda que indivíduos estejam reunidos para que as sensações, afetos e ideias fluam ao ponto de se materializarem como som musical, relação essa da qual estivemos impedidos.

Em meio a tantas incertezas, foi decidido que o Ensemble Bach 21, uma ação de cultura da Universidade Federal de Mato Grosso do Sul, não iria cessar seus trabalhos e que iria buscar novas formas de integrar a pesquisa de seus membros, de modo a manter uma produção artística viva e significativa para este momento. Nesse contexto, o presente trabalho teve início, tanto do ponto de vista da reflexão teórica, quanto de sua realização prática. O artigo apresenta, portanto, discussões e interações com a bibliografia proposta exatamente na ordem que surgiram, de acordo com as necessidades práticas de se construir uma interpretação musical conjunta mesmo que em ambientes afastados e distintos. Desse modo, relata as etapas metodológicas de uma pesquisa artística de caráter experimental que conduziram ao objetivo final deste trabalho: realizar uma nova interpretação da canção Morro Velho. 


\section{Criação \&}

\section{Uma canção, várias realizações}

Em entrevista concedida a Arrigo Barnabé para o programa de rádio Supertônica, veiculado em 20 de janeiro de 2020, o violoncelista Antonio Del Claro contou detalhes sobre a gravação da canção Morro Velho, que fez ao lado de Milton Nascimento, ao violão, e de Elis Regina, que ostentava ali a gravidez de Maria Rita ${ }^{5}$. A gravação foi feita com o arranjo do então marido de Elis, César Camargo Mariano, que estava a produzir o álbum Elis, de 1977. No relato, o violoncelista torna clara a facilidade com que os envolvidos lidaram com aquela canção já bastante conhecida de todos naquele momento, facilidade essa que impressiona quem escuta a faixa resultante, que produz uma densidade emotiva que faz da gravação lendária diante de outras não menos importantes.

No entanto, escutar a entrevista foi ainda mais significativo quando, já em meio à pandemia de 2020, o Ensemble Bach 21 estava exatamente a realizar um levantamento de repertório para uma formação tão atípica como a que possuía naquele momento: violoncelo, viola caipira e voz feminina. Já que o propósito da formação é ser um "grupo instável", que se modifica ano a ano de acordo com as pesquisas de iniciação científica de alunos do curso de música da UFMS, essa etapa se mostrou muito reveladora, apontando direções artísticas para os provenientes projetos de todos. O repertório já possuía peças como o Prelúdio VII, do professor da UFMT, Roberto Victório, para viola e voz, e Duas Distâncias, para 2 instrumentos de cordas e voz, escrita pelo professor da USP, Silvio Ferraz, sobre textos de Martin Codax e Annita Malufe. A canção de Milton Nascimento na gravação de Elis Regina se mostrou, dessa forma, o complemento perfeito para um projeto que pretendia escapar, por um lado, dos estereótipos regionalistas da viola caipira e, por outro, dos estereótipos eruditizados do violoncelo, sendo a voz a amálgama que ligaria todos os mundos envolvidos. Justamente a voz de Elis, com sua projeção sonora focada, constituindo um modelo de sonoridade para todo o projeto.

Contudo, por mais que a gravação do álbum de 1977 fosse emblemática, fazia-se necessário que o grupo conhecesse mais a fundo as propriedades ocultas que a canção possuía em suas profundezas históricas e musicais, que dela pudessem ser extraídas em uma nova leitura. Nessa direção, seria óbvio chegar à primeira gravação realizada por Milton Nascimento com arranjo de Luis Eça em seu álbum de estreia de 1968, Travessia, que originalmente seria simplesmente intitulado Milton Nascimento. A famosa canção que deu título ao álbum foi a segunda colocada do Festival Internacional da Canção de 1967, mesmo concurso no qual a canção Morro Velho fora contemplada com a sétima colocação. Na escuta da gravação original, todavia, algumas das singularidades da versão de Elis sumiam: não havia o violoncelo, o andamento mais lento e a flexibilidade quase hesitante da voz de Elis. Além disso, saber que o violão permanecia sendo tocado

Disponível em: <https://radios.ebc.com.br/supertonica/2020/01/antonio-del-claro-esta-nosupertonica-desta-segunda> 


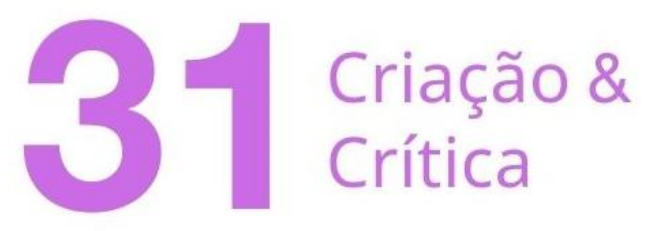

por Milton demonstrava que a direção de César Camargo Mariano para o arranjo foi bastante específica quanto ao resultado que buscava.

Além disso, seriam somadas às gravações antológicas feitas em estúdio por Milton e Elis outras importantes gravações ao vivo, as de Milton feitas em 1975, 1987 e 2013, e a de Elis em 1977, incluindo também a regravação em estúdio, presente no disco de Milton, Yauaretê, de 1987, com arranjo bastante diverso dos demais, escrito por Jorge Callandrelli.

A letra da canção segue em sua forma original, para que posteriormente possamos citar algumas das imagens mais célebres de sua construção e, na seção oportuna, os meios musicais para tanto.

"No sertão da minha terra

Fazenda é o camarada que ao chão se deu

Fez a obrigação com força

Parece até que tudo aquilo ali é seu

Só poder sentar no morro

E ver tudo verdinho, lindo a crescer

Orgulhoso camarada

De viola em vez de enxada

Filho de branco e do preto

Correndo pela estrada atrás de passarinho

Pela plantação adentro

Crescendo os dois meninos, sempre pequeninos

Peixe bom dá no riacho

De água tão limpinha, dá pro fundo ver

Orgulhoso camarada

Conta histórias pra moçada

Filho do sinhô vai embora

Tempo de estudos na cidade grande

Parte, tem os olhos tristes

Deixando o companheiro na estação distante

'Não me esqueça, amigo, eu vou voltar'

Some longe o trenzinho ao Deus-dará

Quando volta já é outro

Trouxe até sinhá mocinha para apresentar

Linda como a luz da lua

Que em lugar nenhum rebrilha como lá

Já tem nome de doutor

E agora na fazenda é quem vai mandar

E seu velho camarada

Já não brinca mais, trabalha"

(NASCIMENTO apud NUHA, 2017, p. 44) 


\section{Criação \&}

\section{Pesquisas sobre Milton, Morro Velho e Elis}

O passo seguinte foi a condução de um levantamento bibliográfico sobre pesquisas acadêmicas já realizadas sobre a música de Milton Nascimento e, se fosse possível, em particular sobre a canção que nos era objeto de estudo. Era previsível que "a falta de arcabouços metodológicos capazes tanto de assegurar um tratamento equilibrado à diversidade de tradições do país quanto de levar seriamente em conta seus conteúdos musicais" (TREECE, 2004, p. 332) que acomete o estudo da "canção gravada" 6 iria afetar também este levantamento, que, como demonstrado, reúne em sua maioria estudos feitos a partir de postulados e metodologias com a mesma orientação daqueles "trabalhos acadêmicos defendidos ou publicados sobre música popular até os anos 80 " que em sua maioria "dedicavam-se quase que exclusivamente ao estudo da letra" (OLIVEIRA, 2012, p. 132).

De fato, dentre a bibliografia mais relevante levantada, apenas as dissertações de Rodrigues (2000), sobre a harmonia modal de Milton; Silva (2011) sobre o papel do arranjo em três de suas canções; e Lopes Cançado (2010), sobre os processos criativos das primeiras três canções compostas por Milton, foram publicadas a partir de pesquisas efetivamente da área de conhecimento de Música, assim como os artigos delas extraídos, de maneira que são dos raros os que contemplam questões estruturais para além das letras de Milton. Não se pode excluir dessa categoria os trabalhos de Nunes (2015), sobre a vocalidade de Milton e, especialmente, o artigo de Arcanjo (2011), que, ainda que não lide com questões propriamente musicais e trate de maneira bastante intuitiva a técnica vocal de Milton, oferece uma tipologia muito rica de suas emissões vocais em relações e referências dentro de suas canções. Os desdobramentos culturais e sociais a partir de letras e da biografia de Milton ocupam, previsivelmente, a maior parte da bibliografia existente, como é caso de Silva (2003), sobre a questão da negritude, e Menezes (2018), sobre a influência dos cantos de trabalho em sua música e sua relação com desigualdades sociais no Brasil. A notável presença de uma religiosidade nas canções de Milton é objeto de reflexão em trabalhos da área de Ciências da Religião como em Minami (2009), que trata especificamente da Missa dos Quilombos, e Botas \& Blanco (2013), que aborda um certo panteísmo político expresso em sua música. Sem dúvida, a maior parte dos trabalhos aborda a questão da diversidade e do pluralismo estilístico nas composições de Milton a partir de uma visão da fragmentação social pós-capitalista, como o fazem Souza (2011; 2015), Gueraldo (2017) e Pacheco (2014), junto aos artigos provenientes dessas teses. Somam-se, finalmente, as duas biografias mais populares de Milton, de Duarte (2006) e de

\footnotetext{
${ }^{6}$ A questão terminológica esbarra em entraves metodológicos, epistemológicos e até mesmo ideológicos. A querela em torno do termo 'popular' já é antiga e, de Mário de Andrade aos pesquisadores atuais em estudos culturais, parece não ter obtido solução definitiva. A ideia de 'canção gravada' parece delimitar mais positivamente dois atributos distintivos dessa forma musical criada especificamente no, para e a partir do fonograma, tendo clara inspiração em postulados dos autores do The Cambridge Companion to Recorded Music (2009).
} 


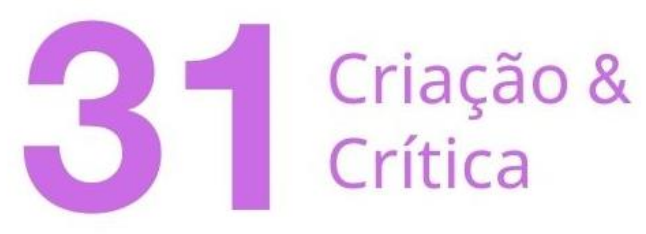

Amaral (2018), que, ainda que não sejam trabalhos acadêmicos devido a seu viés jornalístico, constam sempre como referências muito consultadas nas pesquisas sobre o músico. Como nota final, excluem-se desse levantamento as dezenas de trabalhos sobre a construção de um imaginário mineiro ou brasileiro pelo Clube da Esquina, em relação a questões políticas do regime militar, pela razão de não agregarem com vistas necessariamente originais às presentes questões de pesquisa.

Dentre toda a fortuna crítica levantada, dois trabalhos tratam, em especial, da canção Morro Velho e, por isso, ofereceram pontos de partida bastante importantes para a construção de uma interpretação musical. Campos (2011) se atém à organização formal $A A B A$ da canção para traçar a forma pela qual as imagens construídas na relação entre os dois personagens principais da narrativa caminham para um gradual afastamento até o final da canção. A falta de descrições musicais em relação à estruturação desse discurso, no entanto, exclui a possibilidade de maiores desdobramentos da leitura. Já o artigo de Gueraldo (2018) oferece uma leitura musical mais rica em suas implicações interpretativas. Sua menção a "uma espécie de toada" (GUERALDO, 2018, p. 37), da qual consistiria a linha principal do violão, remetendo a uma sonoridade sertaneja que surge na introdução da gravação original e nos interlúdios entre as estrofes na regravação de Elis, foi muito feliz em sua percepção, ainda que a análise não vá além da mera associação. Na verdade, o efeito é obtido de duas maneiras principais: a primeira, por meio de um violão com cordas de aço, cujo timbre tenso e brilhante remete diretamente à sonoridade da viola caipira, o que é amplificado pela utilização de um "violão Ovation" (NUHA, 2017, p. 44) por Milton na gravação de Elis; a segundo maneira consiste no fato do tema ser formado por duas notas paralelas nas cordas agudas (Fig. 1), o que é uma figuração típica da performance instrumental das modas de viola caipira, conhecida como "ponteado".

Figura 1 - Tema do violão de Morro Velho (Manuscrito de Eumir Deodato)

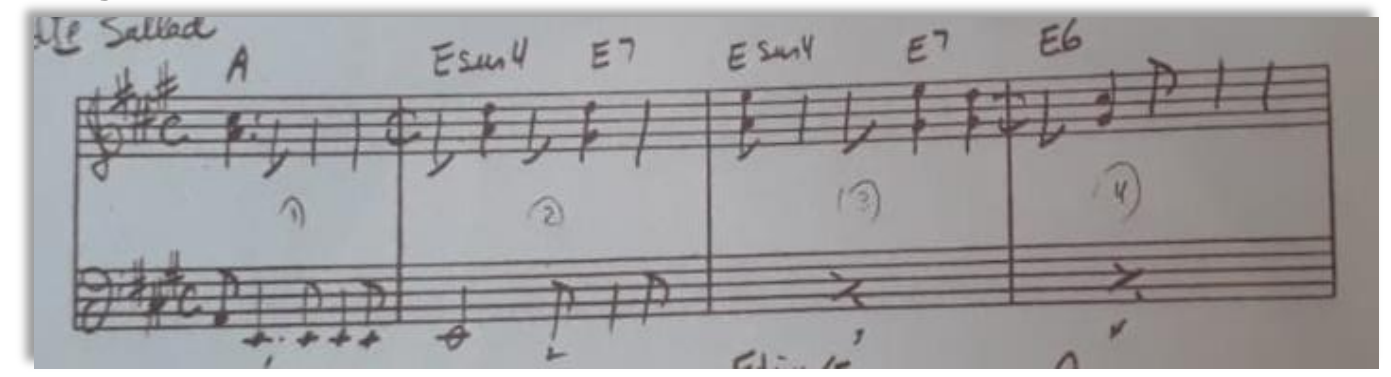

Fonte: NUHA, 2017, p. 46

Essa consideração nos foi muito importante para realizarmos o caminho de volta da associação de Milton com a sonoridade sertaneja, transpondo a linha para a viola caipira, de modo que a escrita do violão se tornou ainda mais confortável na viola em termos de tocabilidade e sonoridade. Isso tornou a adaptação do arranjo 


\section{Criação \&}

quase que uma escrita original, obtendo o resultado procurado de maneira até mais fácil do que se fosse o violão o instrumento utilizado. Mesmo assim, o referencial encontrado ainda deixava muitas lacunas para a interpretação musical e para a construção de uma nova versão gravada à distância.

Em relação a Elis Regina, como a maior parte da pesquisa acadêmica se concentra sobre a "obra" e o "criador", há menor espaço para a análise do intérprete e da performance. A maior parte dos trabalhos, como Lunardi (2014) e Dias (2009), se atem à atuação política de Elis ou aos desdobramentos dessa atuação em relação à televisão e à indústria fonográfica, como Silva (2006). Dois importantes empreendimentos estudam a performance de palco de Elis, com boas representações analíticas, que são Cuellar (2019) e, principalmente, Borém \& Taglianetti (2014). A questão da performance vocal e da estruturação de suas gravações permanece sem estudo adequado.

\section{Análise imanente}

Diante da multiplicidade de gravações e da contribuição, ainda que parcial, da literatura disponível sobre os agenciamentos artísticos envolvidos na canção em questão, o próximo passo para a construção de uma nova interpretação, sobretudo baseada na gravação de Elis, seria estudar os agenciamentos expressivos que a própria escuta proporcionaria. É nesse sentido que adentra o processo uma "análise imanente" à contemporaneidade da escuta, conforme propõe o compositor Silvio Ferraz (2011, p. 54). Trata-se não de aplicar uma máquina teórica abstrata, externa ao discurso, mas partir da temporalidade própria da escuta para fazer as questões que ela realiza. Na verdade, a análise imanente já fora percebida por Jean-Jacques Nattiez em sua proposta de semiologia musical. Em sua proposição de metodologia, ele entendia uma "análise das configurações imanentes de uma obra" (NATTIEZ, 1990, p. 15), distinguindo três instâncias do discurso musical a partir das quais relações possíveis seriam estabelecidas: a análise poética, que estuda o processo de criação de uma obra; a análise estésica, que estuda o processo de recepção de uma obra; a análise imanente, que estuda aquilo que há de materializado ou estruturado em uma obra. No caso da música, essa metodologia obviamente excluiria a performance de uma obra e mais ainda seu processo de construção e preparação. Além disso, uma questão que seria possível nela se complementar seria a fácil presunção da separabilidade entre as três instâncias, como se um compositor não pensasse em como se dará a escuta da música que está a conceber ou o ouvinte não fosse afetado por aquilo que vê e experimenta além do som pura e simplesmente. E mais que tudo, essa noção não considera que a própria obra é uma sedimentação de todas essas forças e que reúne em si um grande conjunto de

\footnotetext{
7 "Em uma análise imanente, conceitos como os de tema, sujeito, contrassujeito, contratema, desenvolvimento, transição, estrutura harmônica ou mesmo intervalar não são pertinentes como a priori analíticos, sua pertinência está apenas na possibilidade de sua contemporaneidade à escuta. Tal estratégia analítica recoloca o tempo em questão e os artifícios da leitura estrutural fora do tempo perdem o lugar de primazia" (FERRAZ, 2011, p. 54)
} 


\section{Criação \&}

relações entre o compositor, seu entorno, o performer e as próprias circunstâncias em que sua realização acontecerá. Sendo assim, a acepção de análise imanente aqui proposta estabelece um olhar centrado não no performer em si ou no compositor, mas na obra, no sentido mais lato do termo, como trabalho, de maneira que o que interessa do performer, do compositor e da escuta é aquilo deles que está implicado no processo perceptivo.

O primeiro aspecto da gravação de Morro Velho por Elis Regina é a ausência de qualquer introdução, diferentemente da gravação original. Essa economia formal resulta em uma ênfase na narratividade do texto e, posteriormente, em uma valorização das seções instrumentais intermediárias. A forma da canção, como já fora mencionado, é um AABA, forma cara a Milton desde sua primeira canção, "Novena" (LOPES CANÇADO, 2010, p. 39). Trata-se de uma canção estrófica, sem refrão, entretanto, com uma terceira estrofe contrastante, que quebra a possibilidade de uma escuta hinológica da canção como um todo. O que afere o contraste para a terceira estrofe é a inserção de uma situação de conflito na narrativa ("Filho do senhor vai embora"), mas também o discurso harmônico da canção.

A canção Morro Velho, conforme composta por Milton, se desenvolve sobre o campo harmônico de Mi Maior, com a reiteração de um pedal sobre a nota Mi durante o tema tocado pela sexta corda solta do violão nos interlúdios. Entretanto, apesar do campo harmônico e da nota pedal, as duas primeiras estrofes se desenvolvem em uma progressão harmônica sobre a região harmônica de Lá Maior, assim como a quarta estrofe em paralelo, enquanto a terceira estrofe demarca o contraste por meio na tonalidade relativa menor de Lá Maior, isto é, Fá sustenido menor, o que seria o suficiente para demarcar a leitura da harmonia sobre o centro de Lá Maior. No entanto, o que acontece é um evento harmônico típico de Milton Nascimento, que é o uso do modalismo como sistema harmônico ao invés do tonalismo (RODRIGUES, 2000), nesse caso, por meio de um Lá lídio, fruto da relação harmônica de Lá Maior com o campo de Mi Maior. O principal atributo do Lá lídio em oposição a um Lá Maior natural é a presença do intervalo de quarta aumentada, neste caso, do Ré sustenido. Isso ocasiona o início da segunda metade das primeira, segunda e quarta estrofes ("Só poder sentar no morro") sobre Ré sustenido menor com sétima menor e quinta diminuta e também o terceiro verso das mesmas estrofes, todas elas a conter o intervalo característico ("Fez a obrigação com força"), o que torna esse verso sempre o ponto mais dramático do texto em cada ocorrência. 


\section{Criação \&}

Figura 2 - Esquema formal de Morro Velho

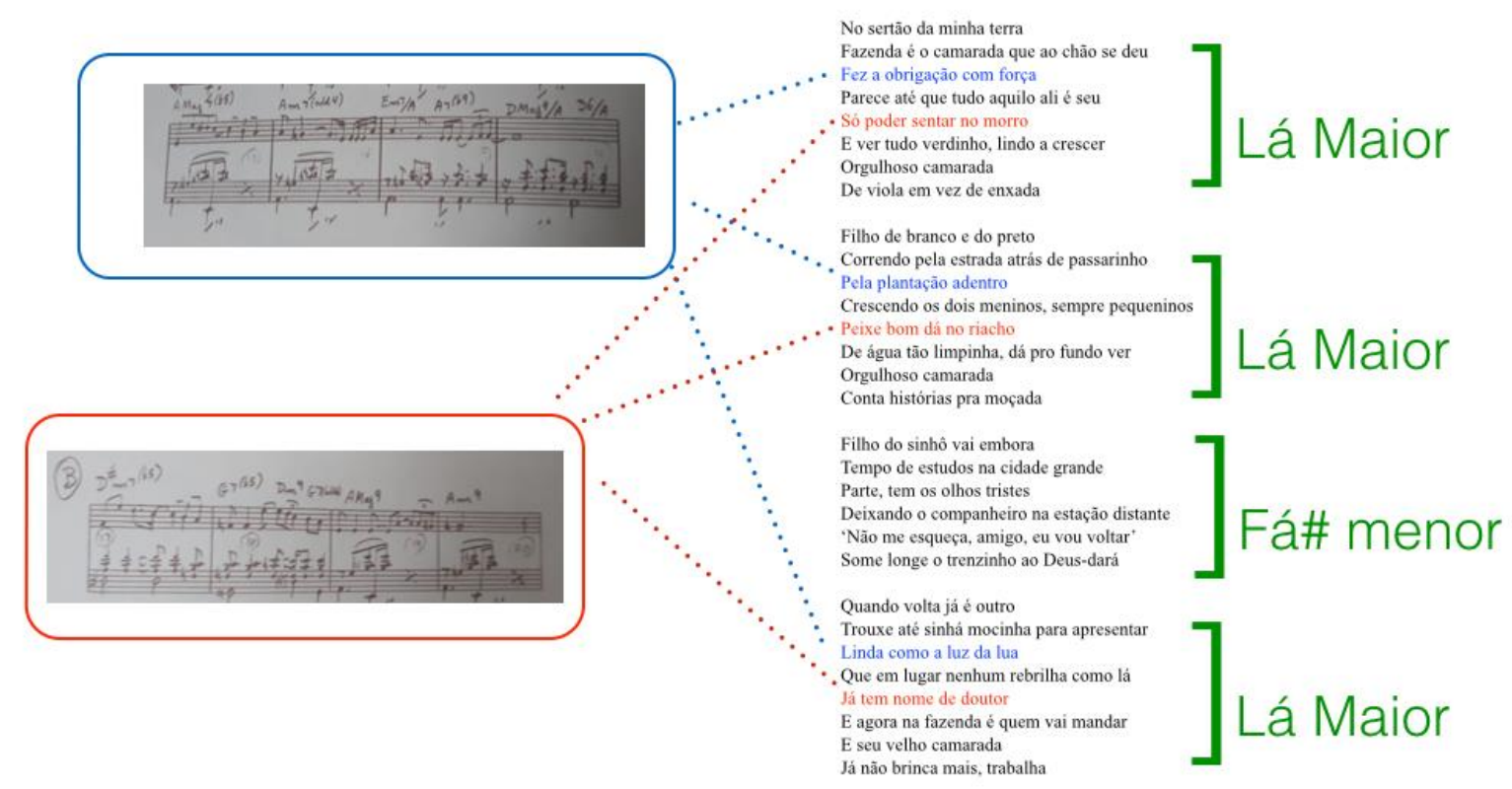

Fonte: Elaborado pelos autores a partir dos manuscritos de Eumir Deodato disponíveis em NUHA, 2017, pp. 46-47

Ademais às questões de cunho estrutural, seria necessário observar a composição da canção gravada dentro de sua natureza própria, isto é, como agenciamento criativo coletivo que encontra materialização não na notação, mas no registro fonográfico. Sendo assim, precisamos mencionar o Milton compositor de 1967, tal qual o Luis Eça arranjador; falar de Elis tal qual César Camargo Mariano. A criação da música gravada é um empreendimento realizado a muitas mãos, contendo minimamente a figura do arranjador e também do produtor, para não falar de uma grande cadeia de profissionais músicos igualmente responsáveis pelo resultado sonoro-musical final. Em nosso caso específico, vale lembrar a distinção feita por Gil Jardim entre "arranjos convencionais" e "arranjos autorais". Sem dúvida o arranjo de Camargo Mariano para o álbum de 1977 se insere na segunda categoria, na medida em que atende ao critério estabelecido por Gil de informar "elementos que se tornam significativos na apreensão perceptiva de determinada canção" (JARDIM, 2016, p. 48). Era exatamente uma força que a realização da forma pelo arranjador e sua redefinição por meio da linha de violoncelo tocada por Antonio Del Claro tornou a todos nós, que buscávamos construir uma nova 


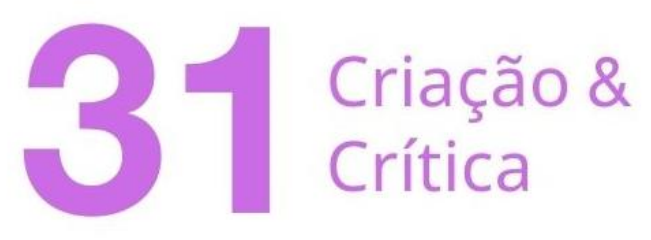

interpretação, o senso de que aquela gravação continha alguma "informação indissociável" (JARDIM, 2016, p. 49) de nossa experiência com a canção. É notável a ousadia de Camargo Mariano em tomar uma canção célebre, entre outras coisas, pelo arranjo que conta com uma orquestra sinfônica completa, mais a banda, ambas presentes quase que durante a canção toda, incluindo uma dobra do contrabaixo na nota pedal do tema, reduzindo tudo em sua nova versão a apenas dois instrumentos, criando uma situação relação de intimidade para a experiência.

$\mathrm{Na}$ versão de César Camargo Mariano para Elis Regina, a canção é transposta para um Dó lídio, sobre o campo harmônico de Sol Maior, mantendo as mesmas relações funcionais da harmonia. A linha de violoncelo (Fig. 3) pontua com ainda maior clareza a leitura da forma AABA feita por César Camargo Mariano. A ausência de introdução valoriza a aparição do interlúdio temático que antecede a segunda estrofe, que tem sua força também amplificada pela utilização do violão Ovation, como mencionado, em uma performance ritmicamente implacável de Milton, com uma sonoridade cortante. Desse modo, a entrada da nova linha de violoncelo traz um segundo personagem sonoro para a segunda estrofe, que apresenta bem 0 par de personagens da própria narrativa ("Filho do branco e do preto") e com eles toda uma nova luminosidade, ainda que sobre a mesma harmonia e a mesma melodia vocal da estrofe anterior. Sendo assim, o arranjo realiza aquilo que é o objetivo de todo bom arranjo, que é tornar desejada a escuta de uma próxima seção, o que é ainda mais louvável quando se trata da repetição de uma estrutura estrófica anterior. Na terceira estrofe, contudo, o violoncelo se cala, deixando a dramaticidade da ruptura entre os amigos para ser realizada de modo solene pela voz; mas não por muito tempo. O clamor do amigo que deixa o outro para trás ("não me esqueça, amigo") traz de volta consigo o violoncelo em sua região mais aguda, de som mais penetrante. No encerramento, uma Coda final relembra o tema do violão, porém com um novo canto descendente do violoncelo, secularmente associado ao lamento e ao pranto (ROSS, 2011, p. 53). 


\section{$31^{\cos 3 \sin ^{2} 2}$ Crítica}

Figura 3 - Parte do violoncelo escrita por César Camargo Mariano

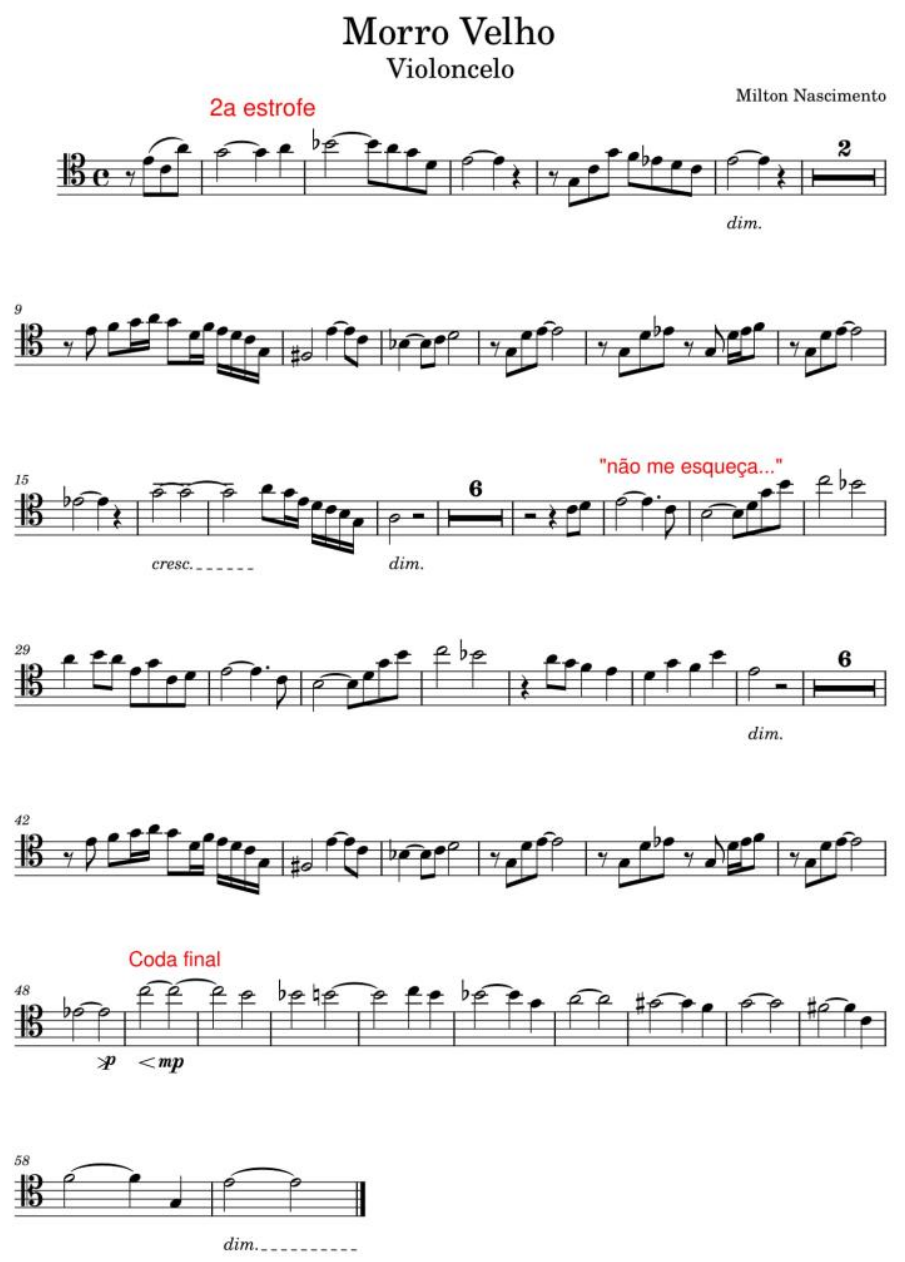

Fonte: Transcrição dos autores

Todavia, os agenciamentos coletivos característicos da canção gravada não terminam até que a música atinja seu derradeiro suporte, isto é, o fonograma. E o responsável pela transdução da música em energia acústica para a música em energia eletromagnética é exatamente 0 produtor musical, entidade criativa que surge com esta nova música no século XX (MOLINA, 2014, p. 23). Com toda transdução ${ }^{8}$ há transformação. É tentador falar que necessariamente há perda, pois

\footnotetext{
${ }^{8}$ Pensamos a ideia de transdução sobretudo a partir do conceito cunhado pelo filósofo francês Gilbert Simondon (1924-1989). Para aplicações musicais do conceito, ver FERRAZ; TEIXEIRA, 2019.
} 


\section{Criação \&}

quando se lê um livro que fora traduzido de outro idioma ao qual o leitor possui acesso, sabe-se bem da possível sensação de frustração que a experiência algumas vezes traz consigo. No entanto, a transdução é transformação, tendo, sim, potencial para perda, mas não excluindo a grande janela para ganhos que passa a existir. Não raras são as performances musicais cuja energia de se estar fisicamente no momento recebendo o som e a força presencial pouco se mantém em um registro, por mais profissionalmente executado que seja. Mas é exatamente o trabalho do produtor fazer do fonograma não o mero registro de uma performance, mas parte essencial do processo de individuação de uma música criada e destinada a ele. Por isso a canção gravada se constitui um artefato artístico diferente de qualquer outro.

Na gravação de Morro Velho por Elis, César Camargo Mariano, o arranjador, acumula também o papel de produtor. Essa dupla função proporciona um uso criativo tanto da gravação quanto da mixagem. O som penetrante do violão toca praticamente as mesmas notas da gravação original, porém com resultado totalmente diverso. A performance vocal é captada com pureza e detalhes aos mínimos ruídos da voz de Elis, rica em microexpressões. O violoncelo abandona a sonoridade convencional dos anos de 1970, quando era comum se dobrar as linhas de instrumentos de cordas para aumentar a robustez do som. A sonoridade se mantém transparente, com todas as ranhuras de uma performance ao vivo, destacando o exuberante vibrato de Del Claro. Contudo, toda a direção da performance e da gravação não seria o suficiente se desaparecesse na amálgama inevitável que os dois canais do estéreo proporcionam. Aqui adentra a genialidade de Camargo Mariano em, a partir da segunda estrofe, quando acontece a entrada do violoncelo, dividir ambos os instrumentos nos dois canais disponíveis, permanecendo apenas a voz centralizada em ambos. A experiência espacial é totalmente imersiva, levando o ouvinte para dentro daquela energia musical entre os três performers. Toda essa força que o binômio criativo Elis Regina e César Camargo Mariano trouxe à nova realização demonstra a razão pela qual, mais do que uma mera regravação, a Morro Velho de 1977 inaugurou uma nova vida para a já célebre canção.

A análise imanente propõe em sua experiência temporal uma busca também pelos vestígios criadores deixados pelos agentes no processo de realização artística. Nesse sentido, foi rica a descoberta no processo de pesquisa artística para essa interpretação do livro Milton Nascimento: letras, histórias e canções (2017), organizado pelo assessor de imprensa de Milton a partir de manuscritos e documentos originais do músico, além de relatos do próprio artista. Interessa, nesse sentido, um breve depoimento que há sobre as situações que ocorreram em torno da composição da canção em questão:

Morro velho tem uma outra história que não vivi, mas que pude imaginar quando criança, nas vezes que ia para a fazenda da tia do Wagner [Tiso]. Lá tinha um empregado chamado Niceto conversando com a gente. E também os 


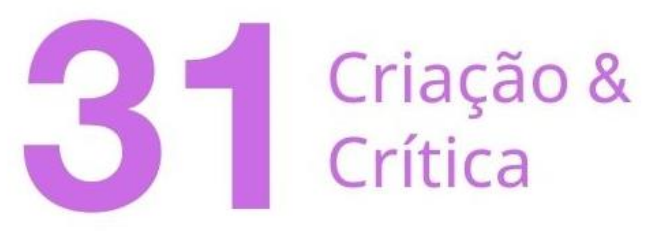

meninos da casa e os da fazenda, que brincavam juntos. $\mathrm{E}$ passava um trem na beira do rio à margem da fazenda. Fiquei com esse cenário todo na cabeça e comecei a imaginar aqueles personagens, por exemplo, o filho do Niceto, amigo dos filhos dos donos da fazenda, que depois iriam embora estudar e já voltariam doutores. Bem mais tarde, essa imagem me voltou à cabeça e compus Morro Velho. E o curioso é que a história que criei acabou acontecendo de verdade. (NASCIMENTO, Milton apud. NUHA, 2017, p. 44)

\section{Discurso lítero-musical}

Após uma primeira análise daquilo em que a escuta da peça nos afeta, procurando entender algumas relações estruturais que causariam tamanha força expressiva, caminhamos para estabelecer algumas leituras mais ampliadas na grande relação formal entre as quatro estrofes da canção e o estabelecimento de um discurso lítero-musical que provesse comunhão tanto com um auditório temporalmente situado, quanto com as novas escutas esparsas no tempo, como aquelas produzidas por nossa futura versão.

Para tanto, as metodologias da análise do discurso ofereceram boas soluções na compreensão de um todo discursivo que incluem suas relações dialógicas. Dentre elas, uma se destaca pela adequação não só à canção gravada, mas, em especial, à MPB: trata-se da tese de doutorado de Nelson Barros da Costa, A produção do discurso lítero-musical brasileiro (2001). Naquilo que nos interessa, a tese se apresenta como uma metodologia efetiva na medida em que reúne a visão dialógica de orientação bakhtiniana e a análise de discurso francesa, com ênfase nas propostas de Dominique Maingueneau. De Bakhtin, importa a forma como ele inclui os diálogos de um texto com outros, tais como a relação de uma canção com outras, ou até mesmo com a literatura ou, como veremos, com o cinema. Também estão incluídos os diálogos com um determinado contexto político, social, ou com demandas locais e regionais.

Soma-se ao componente dialógico da tese de Costa (2001) sua assimilação da análise de discurso de Maingueneau, principalmente na formulação sobre os discursos constituintes, que são aqueles discursos enunciados por uma sociedade com o intuito de fundarem um certo senso de si, ou seja, com um propósito de formar um myhtos comunitário. Na proposta de Maingueneau esse discurso constituinte se articularia por meio de determinados gêneros de discurso, a saber, religioso, científico, filosófico, literário e jurídico. Obviamente, a contribuição de Costa (2001) está justamente em propor a inclusão do discurso lítero-musical como um desses articuladores constituintes. Tem-se afirmado que um dos atributos constitutivos da canção popular é exatamente o senso de "pertencimento" (MOORE, 2012, p. 259) por ela produzido, o que inclusive se usa como dispositivo de mercantilização da cultura. Se esse senso se mostra evidente nas canções 


\section{Criação \&}

populares como um todo, mais ainda o faz quando se trata da produção realizada no Brasil entre as décadas de 1960 e 1970, período em que se constituiu um discurso de resistência ao regime ditatorial vigente e ao qual se cunhou o nome de Música Popular Brasileira. A atribuição da alcunha de discurso constituinte a esse tipo de discurso lítero-musical parece acertada, justamente pelo embate em torno da questão nacional tão presente naquele momento, de modo que, regionalismos à parte, cada canção propunha em seu subtexto um projeto próprio de país e, por que não, de poder político. Seguindo a proposta de Maingueneau para a estrutura do discurso constituinte, Costa parte dos mesmos três componentes de instituição, sendo eles 0 investimento cenográfico, 0 investimento em um código linguístico e o investimento em uma corporalidade, cujas presenças em Morro Velho demonstram tanto a validade da tese, quanto auxiliam na compreensão discursiva da própria canção.

Como fato dialógico, a canção enquanto discurso lítero-musical possui uma cena enunciativa, uma situação espaço-temporal na qual ocorre. Essa cena se configura em três níveis: uma cena englobante, isto é, a situação ampla na qual o discurso está inserido, no caso, a de discurso artístico, portando uma poética própria ao canto; em seguida, a cena enunciativa possui um segundo componente que é uma cena genérica, aqui, é claro, o gênero da canção; em terceiro lugar, a cena possui uma cenografia, constituída pelo próprio texto (COSTA, 2001, p. 74). Essa cenografia possui alguns componentes constitutivos, mas nos interessam principalmente dois: sua topografia e sua cronografia. Esse investimento cenográfico possui um papel central na estrutura discursiva de Morro Velho. Nota-se que a primeira estrofe, na realidade, não apresenta com clareza personagem algum, mas somente a cenografia da canção:

"No sertão da minha terra

Fazenda é o camarada que ao chão se deu

Fez a obrigação com força

Parece até que tudo aquilo ali é seu

Só poder sentar no morro

E ver tudo verdinho, lindo a crescer

Orgulhoso camarada

De viola em vez de enxada

(NASCIMENTO, apud NUHA, 2017, p. 44)

A identidade do enunciador dessa cenografia está apenas velada, o "camarada" trabalhador, de quem nada se sabe ainda. Isso porque a estrofe realiza exatamente um investimento cenográfico em criar tanto a topologia, o sertão e o morro, quanto a descrição de uma realidade agrária servil, ainda que não escravocrata, o que delimita um recorte temporal específico no que tange à realidade brasileira. Aliás, o próprio título da canção demarca os elementos topográfico e cronográfico desse investimento: morro velho. Esse investimento é tão central na canção em questão que tornava complexo nosso pensamento sobre o que se fazer expressivamente com um texto como aquele que não afirmava nenhum 


\section{Criação \&
Crítica}

ponto de vista lírico ou qualquer relação clara entre personagens. Tratava-se apenas de uma grande panorâmica sobre uma paisagem verde, de relevo acentuado, cujo foco se dirige pouco a pouco para uma figura humana que está ali absorvida em seu trabalho, sem nome ou feição definida.

Foi uma novidade quando se descobriu, em meio a esse processo, o vínculo tão essencial da composição de Milton com o cinema:

"A música e o cinema estão ligados. No meu caso, foi um filme de François Truffaut, Jules et Jim, que me inspirou a começar a compor. E cada canção, com ou sem letra, é uma história desenvolvida cinematograficamente, como parte de uma ou várias cenas dirigidas de forma espetacular" (NASCIMENTO apud NUHA, 2017, p. 11)

Essa fala definia bem o papel expressivo da estrofe, uma pintura em movimento de uma sensação, o impressionismo em forma de canção. Quando contemplamos algumas das panorâmicas do filme mencionado por Milton, essa associação termina por se confirmar (Fig. 4):

Figura 4 - Cena em plano aberto de Jules et Jim (1962), de François Truffaut

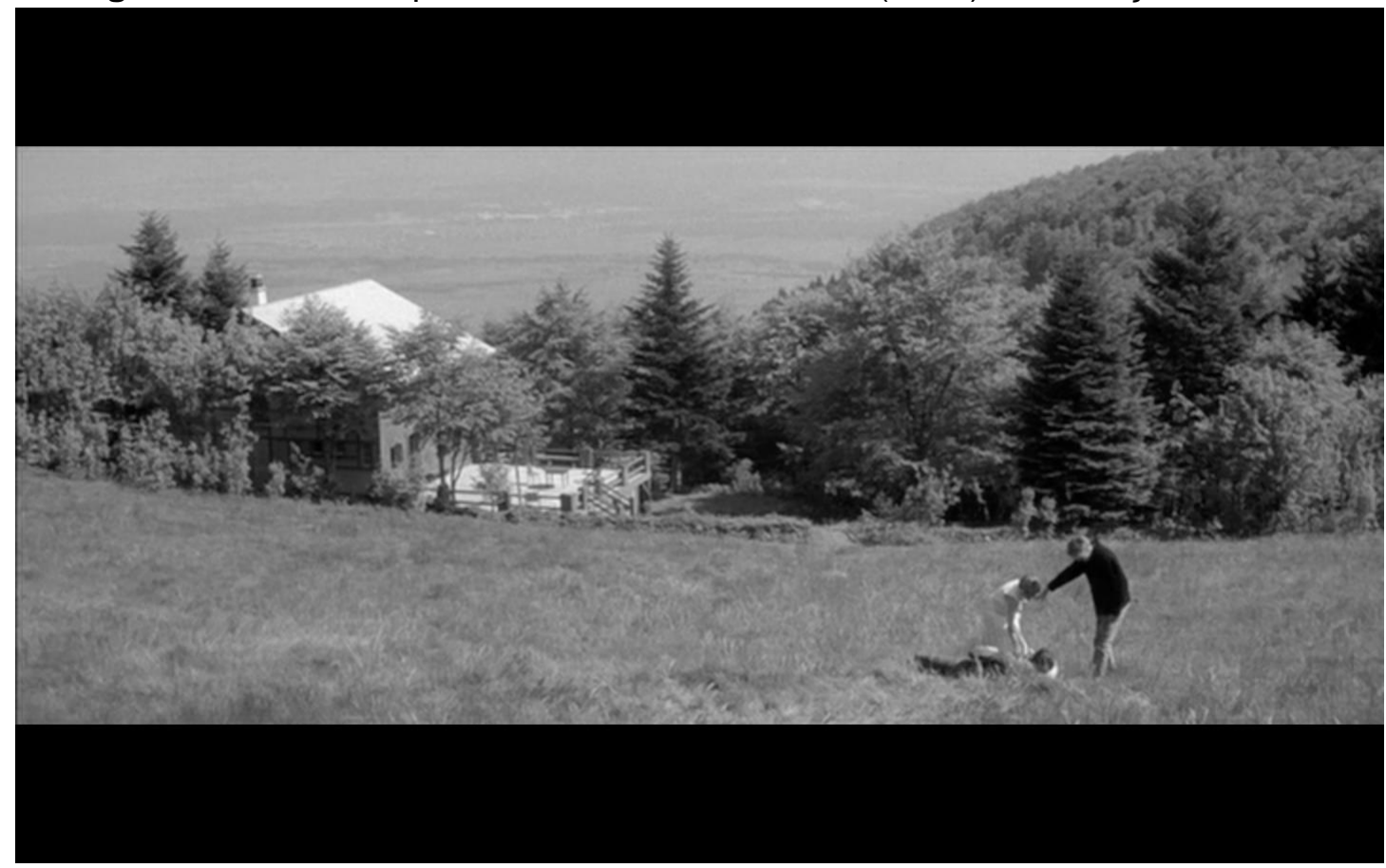

Fonte: Instantâneo do filme, aos 44'38".

Pode-se apenas se especular se a relação entre os dois amigos e sua complicação com a entrada de Catherine (Jeanne Moreau) entre eles possui algum paralelo com o enredo da canção Morro Velho, mas sem dúvida essa transdução 


\section{Criação \&}

oriunda da imagem e do movimento típicos da Nouvelle Vague se faz nítida na maneira de Milton compor sua cena musical diante do morro do sertão mineiro.

O segundo atributo da instituição de um discurso constituinte e, portanto, do discurso lítero-musical como tal, é o investimento em um código linguístico. Esse investimento se define pela instabilidade dos sistemas linguísticos e na negociação que se faz entre aquilo que os autores chamam de "interlíngua" (COSTA, 2001, p.77). Das diversas forças que lutam pela hegemonia de sua forma linguística, restam sempre aquelas marginalizadas e que demarcam uma certa situação de exclusão. No caso da canção de Milton, esse investimento fica evidente com expressões típicas do comportamento submisso demandado do trabalhador rural em suas relações feudais modernas; "sinhô", "sinhá mocinha" e "nome de doutor" são sem dúvida as expressões mais marcantes. Com isso, afere-se não apenas realismo às personagens e suas relações, mas fica clara uma visão crítica desse tipo de relacionamento quando percebe-se a assimetria entre o tratamento submisso e a amizade que parecia haver entre ambos. Musicalmente, o tema que alude à sonoridade da viola contribui igualmente para a efetividade do investimento.

Em terceiro lugar, tem-se o investimento em uma corporalidade como o último componente para a instituição do discurso lítero-musical. A construção de uma voz enunciativa para o texto é necessária na medida em que forma o etos do discurso. Nesse ponto está uma das qualidades na construção do texto por Milton. Ao mesmo tempo em que o investimento anterior forma um etos discursivo pertencente a um campo semântico que pode-se chamar de "filho do preto", outro campo se forma com a linguagem emotiva da declaração "Não me esqueça, amigo, eu vou voltar", pertencente ao campo semântico do "filho do branco". Importante notar, portanto, a justaposição da primeira expressão da segunda estrofe, "filho do branco", para a primeira expressão da terceira estrofe, "filho do sinhô". Abruptamente, aquele que antes era apenas um camarada, filho de uma pessoa branca, transforma-se naquilo que nunca deixara de ser, mas nunca fora percebido: o filho do dono das terras. Aqui pode-se sugerir, inclusive, uma tonalidade polifônica ao texto, tal qual Bakhtin denomina essa "pluralidade de vozes" (BAKHTIN, 1981, p. 93) sem hierarquia narrativa. Ambos os pontos de vista são apresentados com uma sinceridade nunca questionada. A voz crítica não é entoada por nenhum dos dois, mas, na verdade, apenas pela escuta de quem ouve a resignação final do "filho do preto" diante da dura realidade.

\section{Linha vocal e dicção}

De todas as vozes que ressoam na vida de Morro Velho, com certeza todas concordariam que a mais penetrante foi a de Elis Regina. Sua capacidade de extrair novas cores e significados das linhas melódicas mais simples demonstra o lugar essencial da performance na Música Popular Brasileira, seguindo o legado de João Gilberto, aquele que inventou a Bossa Nova não como um fenômeno composicional ou poético, mas como fenômeno essencialmente da performance, já que Eliseth Cardoso havia gravado Chega de Saudades tempos antes de seu violonista, sem maiores 


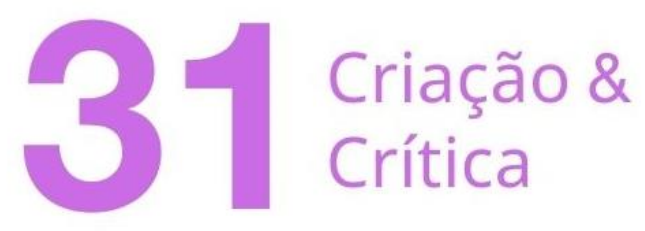

alardes. Nesse sentido, ainda está por ser desenvolvida uma historiografia da música popular que contemple adequadamente o legado de seus intérpretes e, consequentemente, novas metodologias de análise que considerem a performance plenamente.

Daquelas que têm se preocupado com a voz da canção não como um fato meramente estrutural que reúne alturas e palavras, mas como corporificação do discurso, a semiótica da canção de Luiz Tatit figura com relevância. Sua proposta de estudo da "gestualidade oral" (TATIT, 2002, p. 9) sem dúvida é uma importante contribuição, que aproxima a análise da realidade do discurso lítero-musical. Por mais que o desenvolvimento do conceito o filie aos postulados da semiótica tensiva, seria interessante fazê-lo dialogar com a proposta de semiótica musical de orientação peirceana proposta por Silvio Ferraz (1997). Resumidamente, Silvio propõe em sua sistematização uma associação que conecta os postulados de C. S. Peirce sobre a primeiridade (quali-signo; ícone), secundidade (sin-signo; índice) e terceiridade (legi-signo; símbolo) aos conceitos trabalhados pelo compositor britânico Brian Ferneyhough, respectivamente, de textura, figura e gesto. A primeiridade se liga à textura musical, na medida que lidam com o fato sensível; a secundidade se remete à figura musical, pois lidam com as estrutura formais que organizam os códigos musicais; a terceiridade se relaciona com o gesto, pois este é um complexo transmodal que aglutina os dados culturais, sonoros e cinéticos da realização musical. Nessa direção, fica claro que o "gesticulador que manobra sua oralidade" (TATIT, 2002, p. 9) está operando com todo seu aparato vocal diante de um complexo que infunde na enunciação a totalidade do enunciador, com todos seus gestos, sua situação cultural e sua capacidade de evocar referencialmente todo um código que a tradição outorgue em sua comunhão com o auditório. Por isso pensar a proposta de Tatit em diálogo com a de Ferraz pode oferecer vias bastante concretas para a análise, mas, principalmente, para a criação musical.

Tatit considera que a dicção é o limiar que mantém a voz da canção na fronteira entre o canto e a fala e, igualmente, era para nós a construção de uma interpretação baseada na voz de Elis, que talvez seja umas de nossas cantoras que mais habilidosamente se equilibrou nessa corda bamba, que evocou a aplicação do conceito. É importante frisar que todos os atributos da gestualidade oral de Elis aqui mencionados não estão presentes na gravação original de Milton e nem em suas versões ao vivo anteriores a 1977, o que prova seu papel criativo como intérprete e a importância de sua performance na efetividade do discurso resultante.

$\mathrm{Na}$ primeira estrofe, onde o investimento cenográfico do discurso é realizado e se torna um ponto de dificuldade a expressão do texto, Elis opta por uma dicção que enfatiza a simplicidade da descrição sem qualquer afetação. Isso é obtido pela redução de qualquer "tensão passional" (TATIT, 2002, p. 22), com o encurtamento de todas as vogais; o primeiro verso, "no sertão da minha terra", já tem seu fim encurtado, deixando espaço para que o violão soe sozinho. Toda a linha melódica é cantada estritamente a tempo, isto é, alinhada perfeitamente com a rítmica do violão, o que é o oposto da liberdade rítmica característica do canto de Milton, presente já no início da gravação original. Isso significa uma correspondência da "tensão temática" (TATIT, 2002, p. 22) a um nível também reduzido, devido à pouca 


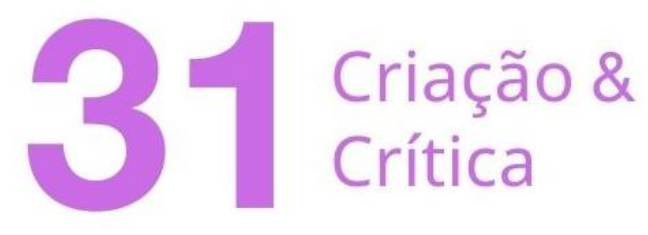

evidenciação dos ataques consonantais. Por fim, vale mencionar que 'r' emitido por vibrante múltipla alveolar bastante pronunciado de Elis, que obviamente suprime a sustentação vocálica, produz já no início o efeito de 'voz falada' próprio à sua performance.

$\mathrm{Na}$ segunda estrofe, o aumento de dramaticidade com a introdução das personagens e seu enredo é estabelecido pela entrada do violoncelo, mas também pela abordagem vocal realizada. Apesar de a linha melódica ser exatamente a mesma da primeira estrofe, o efeito expressivo é totalmente outro, com um crescendo dramático causado tanto pela sustentação das vogais nos finais dos versos, aumentando a tensão passional, e também a mudança drástica de articulação rítmica, sempre deslocando-se do violão de maneira antecipada, causa um efeito de ansiedade que aumenta a pronunciação dos ataques consonantais e, com isso, correspondentemente, a tensão temática da voz. É interessante notar que, nessa estrofe, se destaca uma abordagem vocal de Elis de incluir silêncios que não necessariamente correspondem à pontuação do texto, como em "peixe bom... dá no riacho", o que produz um efeito de suspensão e expectativa à escuta.

A terceira estrofe, que modula harmonicamente sem qualquer transição instrumental, tem na gestualidade oral de Elis mais uma mudança drástica de emissão. É notável que a voz é "colocada" com maior projeção, aumentando assim suas capacidades de modular a expressividade técnica. Sua narração em "parte, tem os olhos tristes" possui um caráter quase testemunhal devido às pausas que realiza entre cada unidade da oração, o que difere radicalmente da performance vocal de Milton, que nesse trecho mantem todas as palavras de cada verso inteiramente ligadas, ignorando inclusive as pontuações. O grande clímax da peça no clamor de "não me esqueça, amigo" é realizado com maestria. A tensão passional atinge seu ápice com uma sustentação de todas as vogais, porém 0 recurso expressivo realmente responsável pelo efeito dramático é a colocação de um vibrato extremamente rápido, que faz o som da voz se confundir com o pranto. Finalmente, na sustentação final de "Deus-dará", a voz é sustentada até o ponto de quase lhe faltar ar, deixando a sonoridade quebradiça demonstrar essa partida.

Finalmente, a quarta estrofe retoma o mesmo material melódico das duas primeiras e, mais uma vez, é a performance de Elis a responsável por torná-la totalmente nova diante do texto. A voz colocada da terceira estrofe se mantém e aqui cria um caráter totalmente resoluto, sem a dramaticidade passional que the antecedeu. Ambos os níveis de tensão são novamente reduzidos, com exceção da frase em modo lídio, "linda como a luz da lua", que é o ponto culminante da estrofe. No último verso, os parônimos "mas" e "mais" são objetos de uso expressivo por Elis, no sentido em que sua inserção de silêncios não correspondentes à pontuação produz uma ambiguidade sobre se o que o verso diz é "não brinca mais, trabalha" ou "não brinca, mas trabalha", mantendo uma polissemia interessante em ambos os sentidos possíveis para a expressão da frase em questão.

A última contribuição original de Elis para a gravação é a inserção de um vocalize final, com uma voz mais uma voz quebradiça, isto é, sem a projeção anterior, com uma sonoridade lontana (distante), como se diria na escrita musical. Essa melodia emerge da última referência ao trabalhar do "filho do preto", o que cria 


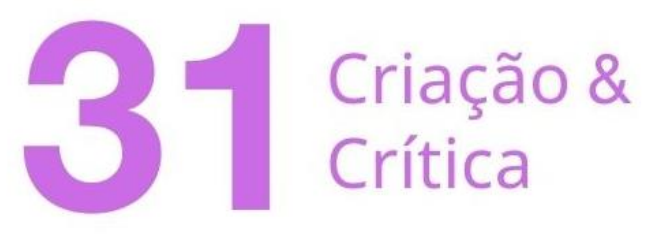

uma associação bastante direta com um canto de trabalho, como aquele cujo reles empregado se manteria cantando em sua resignação final.

Essas descrições apontam as principais contribuições da própria Elis para a constituição do discurso lítero-musical de Morro Velho, de modo que evidencia a importância de se considerar a performance como parte integrante da análise da canção. A partir desse levantamento geral e das reflexões por ele suscitadas, tornou-se possível se pensar em uma interpretação que partisse dos usos retóricos de todos os elementos estruturais considerados, o que mais do que uma mera análise, produz novas vias para a criação musical.

\section{Considerações finais}

O compositor retrata nessa letra a interação total do homem com a terra, a qual, com suas próprias mãos calejadas pelo esforço e doação, ele fez produtiva, daí emanando o orgulho ("orgulhoso camarada") em contemplar sua obra, seu mundo.

Para além dessa relação de dependência homem/campo/obra, existe ainda, no plano das relações humanas, no início da composição, uma leitura positiva do momento, a convivência harmônica, a amizade entre o filho do branco e o do preto na infância ("conta histórias pra moçada"), imagens que projetam a nostalgia do passado prazeroso, idealizado ("peixe bom dá no riacho de água tão limpinha, dá pro fundo ver"), sugerindo a pureza e a inocência dessas relações ainda não contaminadas pelo exercício do poder e da dominação sobre aquele feito pela hereditariedade o mais fraco.

Entretanto, no decorrer da narrativa, com a separação dos amigos, a leitura do presente já não é a mesma, momento em que não se pode vislumbrar qualquer chance de prosperidade, os rumos são opostos, legando ao negro sempre a mesma sina: servir a seu antigo amigo, agora o senhor das terras, o que faz emergir um profundo abismo no âmbito das relações de trabalho, o branco proprietário e o negro vassalo ("E seu velho camarada, já não brinca mais, trabalha").

Pode-se, nesse ponto, visualizar o viés ideológico da letra: uma crítica severa ao modelo de sociedade vigente no que tange às relações entre patrões e empregados, análoga às relações entre senhores e escravos, experiência que remete à biografia do próprio Milton, um menino negro criado por pais brancos em uma cidade interiorana de hábitos rurais. Ao homem liberto de hoje resta apenas o papel social que lhe cabe, o de subalterno, acrescido da marginalização, da pobreza e do subemprego pela falta de oportunidades e incentivos.

Enfim, as relações de amizade aproximam o homem do homem, acontecem em contextos restritos, limitados, contudo se deterioram e se esvaem em decorrência das adversidades sociais e étnicas. Amizade essa que, mesmo à distância, pode unir diferentes em torno de um objeto de comunhão, objeto esse que a música tem se apresentado a ser abundantemente a toda a humanidade. Sendo assim, a melhor e talvez única forma de encerrarmos essa reflexão seja convidando o leitor a comungar conosco de nossa música, que mesmo gravada à distância pôde nos fazer próximos: https://youtu.be/6YS5Oy45-y0. 


\section{Criação \&}

\section{Referências}

AMARAL, Chico. A Musica De Milton Nascimento. Belo Horizonte: Editora UFMG, 2018.

ARCANJO, Fabrícia do Valle. A voz de Milton Nascimento como parceira das canções? DARANDINA revisteletrônica, Vol. 4, No. 1, 2011.

BAKHTIN, Mikhail. Problemas da poética de Dostoiévski. Tradução de Paulo Bezerra. Rio de Janeiro: Editora Forense-Universitária, 1981.

BORÉM, Fausto e TAGLIANETTI, Ana Paula. Texto-música-imagem de Elis Regina: uma análise de Ladeira da Preguiça, de Gilberto Gil e Atrás da porta, de Chico Buarque e Francis Hime. Per Musi [online], n. 29, pp. 53-69, 2014.

BOTAS, Paulo; BLANCO, Pedro Sol. O Tau da travessia: a teopoética de Milton Nascimento. Caderno Ciência e Fé, Vol. 1, No. 2, 2013.

CAMPOS, Beatriz S. A memória do sertão mineiro na canção "morro velho", de Milton Nascimento. In: CYNTRÃO, Sylvia (Org.). Vivoverso encena: ensaios sobre literatura contemporânea. Brasília: Sylvia Helena Cyntrão, 2017.

COOK, Nicholas; CLARKE, Eric; LEECH-WILKINSON, Daniel; RINK, John (Org.). The Cambridge Companion to Recorded Music. Cambridge: Cambridge University Press, 2009.

COSTA, Nelson Barros da. A produção do discurso lítero-musical brasileiro. Tese de doutorado (Linguística aplicada): Pontifícia Universidade Católica de São Paulo, 2001.

CUELLAR, Davi Coutinho Evangelista Johns. "Transversal do tempo": uma investigação acerca do gesto cênico de Elis Regina no espetáculo apresentado em Lisboa (1978). Dissertação de mestrado (Música): Universidade Federal de Goiás, 2019.

DIAS, Gislene. Elis Regina: uma interpretação do Brasil. Dissertação de mestrado (Ciências sociais): PUC/SP, 2009.

DUARTE, Maria Dolores Pires do Rio. Travessia: a vida de Milton Nascimento. Rio de Janeiro: Record, 2006.

FERRAZ, Silvio. Ciclicidade e kinesis em Circles de Luciano Berio. Revista Opus, v. 17, n. 2, 2011. 


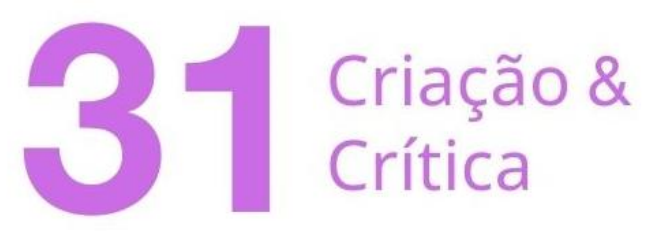

Opus, v. 4, n. 4, 1997.

Semiótica peirceana e música: mais uma aproximação. Revista

FERRAZ, S.; TEIXEIRA, W. Partita 3 para violoncelo solo: preparação de performance depois das notas sobre o fluxo de energia. ARJ - Art Research Journal / Revista de Pesquisa em Artes, v. 6, n. 2, 2019.

GUERALDO, Vinícius J. F. A desumanização social: a nostalgia crítica de Milton Nascimento. Música Popular em Revista, ano 5, v. 2, p. 35-60, jan.-jul. 2018.

. Em busca do consenso: Milton Nascimento e a perda dos laços comunitários. Dissertação de mestrado (Estudos brasileiros): Universidade de São Paulo, 2017.

JARDIM, Gil. O arranjo como estrutura e tecido do discurso musical. Revista USP, no. 111 , pp. $45-58,2016$.

LOPES CANÇADO, Wilson. Novena, Crença e Gira Girou de Milton Nascimento e Márcio Borges: análise de suas três primeiras composições criadas em uma noite de 1964. Dissertação de mestrado (Música): Universidade Federal de Minas Gerais, 2010.

LUNARDI, Rafaela. Elis Regina: entre o canto e a política na década de 1970. Artcultura, v. 16 n. 29, 2014.

MENEZES, Roniere. Cantos de trabalho e linhas de fuga em Milton Nascimento. Revista Brasileira de Literatura Comparada, n. 35, 2018.

MINAMI, Edison. Milton Nascimento e o diálogo inter-religioso na Missa dos Quilombos. Conhecimento e diversidade, v. 1, n. 1, 2009.

MOLINA, Sérgio A. A composição de música popular cantada: a construção: a construção de sonoridades e a montagem dos álbuns no pós-década de 1960. Tese de doutorado (Música): Universidade de São Paulo, 2014.

MOORE, Allan. Song Means: Analysing and Interpreting Recorded Popular Song. Farnham: Ashgate, 2012.

NATTIEZ, Jean-Jacques. Music and Discourse: Toward a Semiology of Music. Tradução de Carolyn Abbate. Princeton: Princeton University Press, 1990.

NUHA, Danilo. Milton Nascimento: letras, histórias e canções. São Paulo: Editora Master Books, 2017.

NUNES, Thais dos Guimarães Alvim. A voz de Milton Nascimento em Presença. Tese de doutorado (Música): Universidade Estadual de Campinas, 2015. 


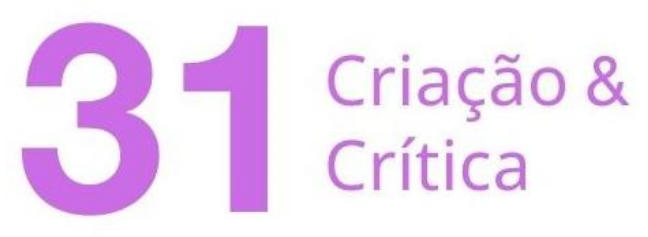

OLIVEIRA, Acauam S. O modelo semiótico de Luiz Tatit e suas implicações na análise da canção popular no Brasil: algumas considerações iniciais. Linguagem Estudos e Pesquisas, vol. 16, n. 2, p. 131-147, jul./dez. 2012.

PACHECO, Mateus de Andrade. Milton Nascimento: num canto do mundo, o conto do Brasil. Tese de doutorado (História): Universidade de Brasília, 2014.

RODRIGUES, Mauro. O modal na música de Milton Nascimento.

Dissertação de Mestrado (Música), Conservatório Brasileiro de Música, 2000.

ROSS, Alex. Escuta só: do clássico ao pop. Tradução de Pedro Maia Soares. São Paulo: Companhia das Letras, 2011.

SILVA, Kristoff. Contribuições do arranjo para a construção de sentido na canção brasileira: análise de três canções de Milton Nascimento. Dissertação de mestrado (Música): Universidade Federal de Minas Gerais, 2011.

SILVA, Carlos Alberto Silva da. A negritude através de Maria Maria de Milton Nascimento. Dissertação de mestrado (Letras): Universidade Federal de Santa Catarina, 2003.

SILVA, Alexandre Rocha da. Elis Regina e a música televisual brasileira. Revista Galáxia, São Paulo, n. 12, p. 43-54, dez. 2006.

SOUZA, Alberto Carlos de. As viagens de Milton Nascimento. Revista Travessias, Vol. 5, no. 2, 2011.

. Uma história da diversidade cultural das sensibilidades

na MPB no tom de Milton Nascimento. Revista Ecos, Vol. 19, No. 2, 2015.

TATIT, Luís. O cancionista: composição de canções no Brasil. $2^{\mathrm{a}}$ edição. São Paulo, Edusp, 2002.

TREECE, David. Melodia, texto e O cancionista, de Luiz Tatit. Revista TeresaRevista de Literatura Brasileira. FFLCH/Editora 34, n. 4 e 5, 2003.

Recebido em: 30/08/2021

Aceito em: $27 / 11 / 2021$

Referência eletrônica: TEIXEIRA, William et al. Subindo o morro velho: notas para a preparação de uma performance. Criação \& Crítica, n. 31, p., dez. 2021. Disponível em: <http://revistas.usp.br/criacaoecritica>. Acesso em: dd mmm. aaaa. 